\title{
An Analysis of Herd Behaviour in China's Securities Investment Fund
}

\author{
Shasha Li \\ School of economic management, Nanjing university of Science and Technology, Nanjing 210094, China
}

2567113013@qq.com

Keywords: securities investment funds Herd Behavior Reason

\begin{abstract}
With the development of economy, the proportion of securities investment funds in China is increasing, and more and more retail and institutional investors are involved in it. Therefore, it is very necessary to study the investment behavior of securities investment funds. In this paper, we use LSV model to analyze herding behavior in securities investment funds, and explore the causes and Countermeasures of herding behavior in China, so as to provide investors and financial regulators with their own views on herding behavior.
\end{abstract}

\section{The background and the present situation}

In recent years, China's financial market has been more and more perfect, attracting a large number of retail investors and institutions. By the end of November 2016, there were 2,722 mutual funds in China, up 43.49\% from the end of 2014.there were 108 domestic fund management companies. In November 2016, the total size of the bond fund increased by 91 billion 981 million yuan, up to $7.03 \%$. All these data show that the scale of China's securities investment fund is expanding year by year. But with the addition of large institutional investors, China's financial market has not become more stable, let us rethink the stock market crash of 2015, except the relevant policy factors, the herd effect also has an inevitable responsibility in this process. We can see that the fund investment strategy is more and more similar, different investment styles tend to be consistent, even in the choose a hobby and shareholding, etc., also more and more similar, these performance reflects the significant of securities investment fund in our country were herd behavior.

\section{Literature review}

Keynes (1936) first proposed the "herd behavior", namely the famous "beauty theory". Then Avery and Zemsky (1998) defined herd behavior as a market trend that allowed private information to be followed by investors who opposed it [1].

Scharfstcin and Jeremy (1990) think when most fund managers don't know their own ability, will ignore their mastery of the private information, copy other fund managers' investment decision to prove their abilities, so the herd behavior [2]. Roll (1992) and Brennan (1993) based on the viewpoint of remuneration explain why the emergence of herd behavior [3]. Liang lu (2012) believed that fund managers lacked effective incentive and restraint mechanism, the information source of fund companies was highly similar, and information asymmetry was the cause of the formation of herd behavior in China [4].

Shen junjie (2009) concluded that the fund's herd behavior is negatively correlated with fund performance through empirical analysis [5]. Zhang yanliang et al (2013) believed that The herd effect deviates from the value investment idea and has a great influence on the volatility of the stock market [6].

\section{Empirical research on herd behavior of securities investment funds in China}

\subsection{Selection of empirical research model of herd behavior}

This paper adopts the revised LSV method of wermers (1999) to test the herd behavior of 
China's securities investment fund. LSV herding behavior measure method defines HM (I, t) as an indicator of herd behavior during t period.

$$
\begin{aligned}
\operatorname{HM}(i, t) & =|P(i, t)-E[P(i, t)]|-A F(i, t) \\
P(i, t) & =\frac{B(i, t)}{B(i, t)+S(i, t)} \\
A F(i, t) & =E|P(i, t)-E[P(i, t)]|=E|P(i, t)-P(t)|
\end{aligned}
$$

Among them, P (I, t) is the proportion of fund managers who buy stock I in a given quarter. B (I, t) $(S(I, t))$ is the number of fund managers who net buy (net sell) stock $I$ in a given quarter. For $E$ [P $(I, t)$, LSV uses $P(I, t)$ of all stocks to replace the arithmetic mean $P(t)$ of the given quarterly $t$. AF is the adjustment factor. As the number of funds participating in the stock exchange ( $N(I, t)$ ) decreases.

$$
\mathrm{HM}=\frac{1}{\mathrm{~N}} \sum_{\mathrm{i}=1}^{\mathrm{N}} \mathrm{HM}(\mathrm{i}, \mathrm{t})
$$

As above, HM is average herd value, we make hypothesis test to the overall sample (5), if the result reject the null hypothesis, shows significant herding effect, if it accept the null hypothesis, then there is no significant herding effect.

$$
\mathrm{H0}: \mathrm{HM}=0 \quad \mathrm{H} 1: \mathrm{HM} \neq 0
$$

Wermers (1999) on the basis of the LSV model and put forward the two indicators, the buyer sheep effect index BHM (I, t) and seller sheep effect index SHM (I, t), the two index can reflect the severity of the herd behave when fund managers buy and sell stocks, the greater its value the more serious its herd behavior.

$$
\begin{aligned}
& \operatorname{BHM}(i, t)=\operatorname{HM}(i, t) \mid P(i, t)>E[P(i, t)] \\
& \operatorname{SHM}(i, t)=\operatorname{HM}(i, t) \mid P(i, t)<E[P(i, t)]
\end{aligned}
$$

We can also calculate the arithmetic mean of BHM (I, t) and SHM (I, t), and compare their size to reflect the severity of the herd effect when the fund manager buys or sells stocks. By using the buyer's (seller's) herd behavior index, it is easy to further explore which herd behavior is more significant when buying and selling stocks, and can compare them.

\subsection{Data source and processing}

The research object is 50 open stock funds, and the data source is the wind database from the fourth quarter of 2015 to the third quarter of 2016. The former 10 stocks held by the fund is the research object. According to the change in the number of shares held by the fund in the next quarter, the amount of the fund's purchase and sale of the stock is calculated.

Organize, and analyze the portfolio data released quarterly by the foundation, and do the following processing for the raw data:

(1) the changes in the amount of holdings caused by the allocation, conversion, and delivery of shares are eliminated through the investment portfolio announcement.

(2) Considering that if a stock is held by a few people, it will not be possible to form herding behavior. therefore, if for stock $\mathrm{i}$ in quarter $\mathrm{I}$, the number of funds involved in buying and selling less than or equal to two, do delete processing. ST and PT shares are not included in the research scope.

(3) the securities investment fund, which entered the top 10 stocks due to the purchase of new shares, was deleted due to the lack of comparability.

(4) it is assumed that the fund's buying or selling of stocks in one quarter is completed.

\subsection{The empirical results of the herd effect LSV in China}

Through the statistics of sample fund data, the number of investment in stock trading in each quarter of 2015 - 2016 is shown in table 1. 
Table 12015 - 2016 number of stocks invested in stock trading

\begin{tabular}{|c|c|c|c|c|}
\hline \multirow{2}{*}{ project } & 2015 year & \multicolumn{3}{|c|}{2016 year } \\
\cline { 2 - 5 } & $\begin{array}{c}\text { Fourth } \\
\text { quarter }\end{array}$ & first quarter & $\begin{array}{c}\text { Second } \\
\text { quarter }\end{array}$ & $\begin{array}{c}\text { Third } \\
\text { quarter }\end{array}$ \\
\hline The number of funds to buy stock & 63 & 165 & 142 & 147 \\
\hline The number of funds to sell stock & 106 & 94 & 52 & 105 \\
\hline
\end{tabular}

According to the data obtained, the herding behavior of 2015 to 2016 in different quarters was calculated, and the results were shown in Table 2 as shown below.

Table 22015 to 2016 test results for herd behavior in different quarters

\begin{tabular}{|c|c|c|c|c|}
\hline \multirow{2}{*}{ Index of herd behavior } & 2015 year & \multicolumn{3}{|c|}{2016 year } \\
\cline { 2 - 5 } & Fourth quarter & first quarter & Second quarter & Third quarter \\
\hline$\square \overline{\mathrm{HM}}$ & 0.1042 & 0.1676 & 0.0222 & 0.0504 \\
\hline$\square \overline{\mathrm{BHM}}$ & 0.0199 & 0.1287 & 0.01865 & 0.0252 \\
\hline$\square \overline{\mathrm{S}} \mathrm{HM}$ & 0.08437 & 0.0389 & 0.00355 & 0.0252 \\
\hline
\end{tabular}

According to the historical experience of using the LSV method by scholars at home and abroad, the magnitude of the size of the HM value is about the severity of herd behavior, as shown in table 3.

Table $3 \mathrm{HM}$ and the severity of herd behavior

\begin{tabular}{|c|c|c|c|c|}
\hline HM & $0-0.1$ & $0.1-0.2$ & $0.2-0.5$ & $0.5-1$ \\
\hline Herd behavior severity & Not significant & Slight & serious & Very serious \\
\hline
\end{tabular}

From Table 2, we can see that during different quarter, maximum HM was 0.1676, the minimum was 0.0222 , they all were significant, which means that if there are 100 funds involved in a single stock exchange, there will be more than $16.76 \%$ of the funds in the same direction buy or sell. Refer to table 3, on average, China's stock market funds do exist slight herding behavior. As can be seen from Table 2, the SHM value of the fourth quarter of 2015 is significantly greater than the value of $\mathrm{BHM}$, indicating that the seller's herd behavior is slightly obvious during this period. In the first quarter of 2016, the BHM value was significantly greater than the value of SHM, indicating that the behavior of the buyer's herd was slightly obvious. As the third quarter of 2016 and the fourth quarter are not significant, this article no longer compares the size of the herd behavior between the buyer and the seller.

Through the above analysis, we can see that there is a slight herding behavior in the investment behavior between our stock market, but there is a weakening trend. Therefore, it is necessary for us to analyze the causes of herding behavior in China's securities investment funds.

\section{Analysis of the causes of sheep effect in China's securities investment fund}

The herd mentality of investors. In the securities investment funds, in order to avoid losses and obtain the average earnings, the fund manager tend to ignore their own private information, take the most of the fund manager's investment strategy. When such behavior is concentrated, so-called herd behavior occurs.

Lack of effective evaluation system for fund managers. Investors in securities investment funds cannot understand the quality of fund managers and can only be judged by their previous performance. the fund managers usually imitate most other funds, to avoid a maverick investment decisions bring huge risk to their pay and career, so form a herd behavior.

Information asymmetry. Although institutional investors have more information than individual investors, but most of them are from the same information source, such as annual reports, so inevitably there will be a similar investment decisions, forming a herd behavior.

Influenced by our macro environment. Because our country securities market is still belongs to 
the emerging markets, market system, laws and regulations is not sound, The number of high-quality blue chips is smaller in all trading shares.so It is unavoidable that a good stock appears, the investors flock into it, and then the herd effect is formed.

\section{Suggestion}

Improve the quality of listed companies. In terms of quality, we should focus on developing new industries, cultivating professional talents, and increasing the support for development potential projects. In terms of quantity, on the basis of quality assurance, we increase support for different industries, making all walks of life a large number of excellent enterprises.

We should improve the information disclosure system in the financial market. Creating diversified sources of information sources and establishing a fair and open disclosure system of information. At the same time, the celebrity fund manager's celebrity effect is reduced, and it is forbidden to recommend a stock in public channels so as to avoid the herd effect.

Improve the performance assessment method of fund managers. we should consider the ability of fund managers in many aspects, formulating a reasonable evaluation cycle, stimulate the fund manager's creativity.

The construction of relevant laws should be improved. we need to combine the characteristics of the times, improve the major laws and regulations in time, and increase the strength to combat the behavior of the financial market.

\section{References}

[1] Avery, Zemsky. Multidimensional Uncertainty and herd behaviour in financial markets[J]. American Economic Review,1998(1):724-748.

[2] Sharfstein David, Jeremy Stein. Herd Behavior and Investment[J]. American Economic Review, 1990.

[3] Roll,R.A Mean Variance Analysis of Tracking Errors[J],Journal of portfolio Management,1992.

[4] Liang Lu. Study on Herding Behavior of China Securities Investment Fund [D]. University of International Business and Economics: Beijing, 2012.

[5] Shen Junjie. An Empirical Study on the relationship between fund managers' quality and fund performance [D]. Chongqing University of Technology: Chongqing, 2009.

[6] Zhang Yanliang, Wang Dongdong, Hu Xiaoyan. An Empirical Study on Herding Behavior of closed-end funds [J]. economic vertical and horizontal, 2013 (9): 139-144. 